\title{
FATORES QUE INFLUENCIAM A COMPRA DE PEIXES POR CLASSE SOCIAL NO MUNICÍPIO DE SANTARÉM-PA
}

\author{
Ana Cely de Sousa Coelho'; Charles Hanry Faria Junior²; Keid Nolan Silva Sousa ${ }^{3}$. \\ ${ }^{1}$ Universidade do Estado do Pará (UEPA), Santarém, Pará, Brasil, anacely_uepa@hotmail.com \\ 2 Universidade Federal do Oeste do Pará (UFOPA), Santarém, Pará, Brasil, charlesufopa@gmail.com \\ 3 UFOPA, Santarém, Pará, Brasil, keid.ufopa@gmail.com
}

\begin{abstract}
RESUMO: O peixe é uma importante fonte proteica na Amazônia e tem consumo influenciado por fatores culturais, sociais e econômicos. O estudo apresenta os fatores que influenciam a compra de peixes em três mercados da cidade de Santarém-PA, realizado de novembro de 2013 a outubro de 2014, mediante o emprego de entrevistas junto aos consumidores. Os dados coletados foram divididos por Classes Sociais e analisados com ferramentas da estatística descritiva. Foram realizadas 923 entrevistas, permitindo estimar que $92,4 \%$ da população local e 90,2\% dos consumidores se enquadram nas Classes Sociais "D" e "E" e 89,6\% reside na Zona Urbana. Ocorre uma escolha pelo local de compra de acordo com a Classe Social e origem do consumidor. Os principais fatores motivadores da compra foram: espécie, oportunidade, preço e saúde e entre os fatores avaliados na compra: espécie, higiene, preço, qualidade e tamanho. A importância dos fatores é diferenciada entre classes sociais. O preço aparece na terceira posição e foi o único fator que ganhou importância na direção das Classes Sociais de menor poder aquisitivo. Os resultados alertam para a necessidade de garantir o abastecimento de peixes de baixo valor comercial e de políticas públicas voltadas ao uso sustentável dos recursos pesqueiros.
\end{abstract}

PALAVRAS-CHAVE: Classe social, Consumo, Motivador, Peixe.

\section{FACTORS INFLUENCING THE PURCHASE OF FISH BY SOCIAL CLASS IN THE MUNICIPALITY OF SANTARÉM-PA}

\begin{abstract}
Fish is an important source of protein in the Amazon and has consumption influenced by cultural, social and economic factors. The study presents the factors that influence the purchase of fish in three markets in the city of Santarém-PA, carried out from November 2013 to October 2014, through interviews with consumers. The collected data were divided by Social Classes and analyzed with descriptive statistics tools. A total of 923 interviews were conducted, making it possible to estimate that $92.4 \%$ of the local population and $90.2 \%$ of consumers fall into the "D" and "E" Social Classes and $89.6 \%$ reside in the Urban Zone. There is a choice of the place of purchase according to the Social Class and consumer origin. The main factors motivating the purchase were: species, opportunity, price and health and among the factors evaluated in the purchase: species, hygiene, price, quality and size. The importance of the factors is differentiated between social classes. The price appears in the third position and was the only factor that gained importance in the direction
\end{abstract}


of the Social Classes of lower purchasing power. The results point to the need to guarantee the supply of fish of low commercial value and public policies aimed at the sustainable use of fishery resources.

KEYWORDS: Consumption, Fish, Motivator, Social class.

\section{FACTORES QUE INFLUENCIAN LA COMPRA DE PECES POR CLASE SOCIAL EN EL MUNICIPIO DE SANTARÉM-PA}

RESUMEN: El pescado es una importante fuente proteica en la Amazonía y tiene consumo influenciado por factores culturales, sociales y económicos. El estudio presenta los factores que influencian la compra de peces en tres mercados de la ciudad de Santarém-PA, realizado de noviembre de 2013 a octubre de 2014, mediante el empleo de entrevistas a los consumidores. Los datos recolectados fueron divididos por clases sociales y se analizaron con herramientas de estadística descriptiva. Se realizaron 923 entrevistas, permitiendo estimar que el 92,4\% de la población local y el 90,2\% de los consumidores se encuadran en las Clases Sociales "D" y "E" y el 89,6\% reside en la Zona Urbana. Se produce una elección por el lugar de compra de acuerdo con la Clase Social y origen del consumidor. Los principales factores motivadores de la compra fueron: especie, oportunidad, precio y salud y entre los factores evaluados en la compra: especie, higiene, precio, calidad y tamaño. La importancia de los factores se diferencia entre las clases sociales. El precio aparece en la tercera posición y fue el único factor que ganó importancia en la dirección de las Clases Sociales de menor poder adquisitivo. Los resultados advierte sobre la necesidad de garantizar el abastecimiento de peces de bajo valor comercial y de políticas públicas dirigidas al uso sostenible de los recursos pesqueros.

PALABRAS CLAVE: Clase social, Consumo, Motivador, Pescado.

\section{INTRODUÇÃO}

A pesca é uma atividade econômica, social e cultural de grande importância na Amazônia, considerada como uma das atividades produtivas mais antigas $d a$ região (LOPES, 2010; ISAAC; ALMEIDA, 2011; COSTA et al., 2013; FARIA-JÚNIOR, 2013) e onde os peixes têm destaque como principal fonte de proteína (ISAAC; RUFFINO, 2000; LOPES et al., 2010; FREIRE, 2014).

Na Amazônia Brasileira, onde se insere a cidade de Santarém - Pará, o consumo per capita de peixes entre zona urbana e rural varia de 18,3 kg/ano a 294,0 kg/ano (CERDEIRA et al., 1997; GANDRA, 
2010; ISAAC; ALMEIDA, 2011), porém, assim como ocorre para distintos produtos e serviços disponibilizados aos consumidores, a decisão de compra é influenciada por fatores culturais, sociais, psicológicos e pessoais (KOTLER; KELLER, 2006; CHAUVEL; MATTOS, 2008; KARSAKLIAN， 2008; KOTLER， 2009; SARTORI; AMÂNCIO, 2012 SILVA et al., 2015), que refletem a opção em adquirir ou não um determinado produto, bem como a escolha do local de compra.

No contexto da escolha do local de aquisição dos peixes, estudos indicam que os consumidores preferem comprar peixes em mercados ou em feiras livres, onde é possível encontrar uma maior variedade de espécies, origem preferida (extrativismo ou aquicultura), qualidade e menor preço (KUBITZA, 2002; MARIUZZO, 2005; GANDRA， 2010; ROCHA NETO, 2010; MACIEL, 2011; SONODA et al., 2012; SILVA et al., 2016).

Nessa ótica o estudo objetivou apresentar um diagnóstico dos fatores que influenciam a compra de peixes entre três mercados da cidade de Santarém, tendo como referencial econômico principal Classe Social dos consumidores
Santarenos, no intuito de contribuir no entendimento dos fatores motivadores de escolha da espécie alvo e do local de compra, bem como colaborar para a implementação de políticas públicas voltadas ao mercado pesqueiro regional.

\section{MATERIAL E MÉTODO}

\section{ÁREA DE ESTUDO}

O estudo foi realizado em três pontos de comercialização de peixes localizados na cidade de Santarém, Estado do Pará, que tem uma área geográfica de 22.886,76 km² e uma população de 294.580 mil habitantes (IBGE, 2012).

O Mercadão 2000, inaugurado em 1985, é o maior em termos de área. Dispõe de espaço destinado a comercialização de frutas, verduras, legumes, produtos naturais (plantas medicinais e óleos naturais), artesanatos, equipamentos caça e pesca, carnes, peixes e derivados (farinha de peixe). A área destinada a comercialização de peixes é composta por 50 boxes onde são disponibilizados peixes in natura e secosalgados, derivados do extrativismo e cultivo. 
A Feira do Pescado foi inaugurada em 2010 e conta com 41 boxes de venda de peixes onde são disponibilizados peixes in natura e seco-salgados, derivados do extrativismo e cultivo. O local é subdividido em duas áreas, uma destinada a permissionários (feirantes) e outra aos pescadores, que vendem sua produção diretamente aos consumidores.

O Mercado Modelo foi inaugurado no ano de 1966, contém 46 boxes de venda de peixes, onde são comercializados peixes in natura e secosalgado de origem extrativa e de cultivo. Seu diferencial em relação aos mercados estudados é a maior disponibilidade de peixes seco-salgado, preparado pelos próprios permissionários.

\section{FATORES}

A aquisição e o consumo de pescado podem ser influenciados por diversos fatores, dos quais se destacam os sociais, econômicos, os padrões de consumo alimentar, características pessoais, cultura, estado de saúde e dimensões atitudinais (BARBOSA, 2006; KOTLER, 2006; LOPES et al., 2010; ISAAC;
ALMEIDA, 2011; SOLOMON, 2011; CARVALHO, 2012), porém no presente estudo foram descritos somente os cinco mais relatados pelos consumidores entrevistados.

\section{BASE DE DADOS}

Os dados primários foram coletados mediante a aplicação de entrevistas semiestruturadas (MINAYO, 1998) em uma sub-amostra dos consumidores de Santarém entre os meses de novembro de 2013 a outubro de 2014, no momento da compra no Mercadão 2000, Feira do Pescado e Mercado Modelo. Para homogeneizar o quantitativo de entrevistas entre os mercados selecionados e mitigar vícios no procedimento de coleta, se procedeu a um sorteio semanal para ordenar o local (mercado) e dia de coleta, bem como do consumidor a ser entrevistado, tornando a coleta a mais aleatória possível.

Entre as informações coletadas constam: renda familiar do consumidor, zona que reside (urbana ou rural), número de pessoas na família, quantidade de peixes que compra semanalmente, espécies e preço pago, 
motivo da escolha do local de compra dos peixes, motivadores da compra do peixe e motivadores avaliados na compra.

As informações coletadas foram digitalizadas em planilhas do Excel e analisadas com base na divisão da Classe Social da população Santarena, de acordo com o critério de classificação adotada pelo Instituto Brasileiro de Geografia e Estatística - IBGE (para um Salário Mínimo - SM de R\$622,00 no ano de 2012, ano de referência do censo do IBGE) que diferencia a população Brasileira em Classes de "A" à "E" (IBGE, 2012), modificada pela Fundação Perseu Abramo (FPA, 2013), onde a Classe "A" é composta por famílias com renda acima de 20 SM, a Classe "B" acima de 10 a 20 SM, a Classe "C" acima de 4 a 10 SM, a Classe "D" acima de 2 a 4 SM e a Classe "E" até 2 SM.

Os resultados das consultas foram analisados mediante o emprego de ferramentas da estatística descritiva (ZAR, 1999) e dados secundários foram obtidos de relatórios técnicos de instituições que atuam no setor pesqueiro regional e publicações.
RESULTADOSE DISCUSSÃO

Foram entrevistados 923 consumidores com maior frequência no Mercadão 2000 (36,8\%), seguido da Feira do Pescado (34,0\%) e Mercado Modelo (29,2\%). Nesses mercados o horário de funcionamento se estende das 05:00 às 17:00 horas diariamente, exceto aos domingos, quando funcionam somente no turno da manhã.

CLASSES SOCIAIS E FATORES DE ESCOLHA DO LOCAL DE COMPRA DE PEIXES

A partir da divisão da população Santarena por Classe Social obtida (IBGE, 2012; FPA, 2013) foi possível estimar que 92,4\% da população local se enquadra nas classes D e E (Tabela 1), assim como 90,2\% dos consumidores entrevistados, percentual maior que o observado nos estudos de Silva et al. (2012), Xavier et al. (2013) e Santos et al. (2015), o que aponta para a importância do peixe na alimentação da população de baixa renda de Santarém. Esses consumidores residem em 42 bairros na Zona Urbana (89,6\%) e 55 comunidades da Zona Rural. 
Tabela 1. Classes Sociais da população e consumidores de peixes no município de Santarém-PA.

\begin{tabular}{cccc}
\hline Classe Social & Renda familiar & \% da população & \% de consumidores \\
\hline A & Acima de 20 SM & 0,4 & 0,6 \\
B & Acima de 10 a 20 SM & 0,9 & 1,4 \\
C & Acima de 4 a 10 SM & 6,3 & 7,8 \\
D & Acima de 2 a 4 SM & 9,9 & 43,9 \\
E & Até 2 SM & 82,5 & 46,3 \\
\hline
\end{tabular}

Fonte: Elaborado pelo Autor.

O Mercadão 2000 foi o local de compra da maior parcela dos consumidores das classes "A", "B", "C" e "D" e menor para o Mercado Modelo, ocorrendo o inverso para os consumidores da classe "E" (Tabela 2). Essa preferência pelo Mercadão 2000 pode estar relacionada a existência de áreas agregadas a comercialização dos peixes, onde são oferecidos diversos produtos, como frutas, verduras, remédios caseiros (cultura popular), poupas de frutas, e grãos. Além da existência de supermercados e outros estabelecimentos (lotérica, correios) nas proximidades, proporcionando maior comodidade para os consumidores para comprar outros itens além dos peixes (RODRIGUES, 2004). Para OS consumidores da classe "E", e originários da Zona Rural, a maior frequência no Mercadão Modelo se dá devido à proximidade da estação de parada dos ônibus que vêm das comunidades para o local onde vendem seus produtos (farinha, tubérculos, grãos, frutas legumes e verduras), conhecido como a Feira da Candilha, aproveitando a oportunidade para adquirir peixes salgados para o consumo familiar em decorrência da dificuldade em armazenar e transportar peixes frescos até o local de residência, satisfazendo suas necessidades comerciais e alimentares. Para os consumidores urbanos, a maior procura por esse mercado pode estra relacionada a sua proximidade para o Centro Comercial de Santarém. 
Tabela 2. Origem e distribuição percentual de consumidores de peixes por classe social no município de Santarém-PA por mercado estudado.

\begin{tabular}{clccc}
\hline Classe Social & Zona & Mercadão 2000 & Feira do Pescado & Mercado Modelo \\
\hline A & Urbana & 1,0 & 0,6 & 0,4 \\
B & Urbana & 1,8 & 1,5 & 1,1 \\
\multirow{2}{*}{ C } & Rural & 0,6 & 0,3 & - \\
& Urbana & 9,7 & 5,5 & 6,8 \\
\multirow{2}{*}{ D } & Rural & 3,5 & 3,0 & 2,6 \\
& Urbana & 45,0 & 42,3 & 33,6 \\
& Rural & 4,5 & 4,5 & 12,9 \\
& Erbana & 33,9 & 42,3 & 42,6 \\
\hline
\end{tabular}

Fonte: Elaborado pelo Autor.

Esse conjunto de características que os consumidores Santarenos apresentam se enquadram nos fatores sociais e pessoais descritos por Kotler e Keller (2006) e Teixeira (2010) corroboram com os estudos desenvolvidos por Semenik e Bamossy (1995) e Boone e Kurtz (1998), onde destacam que ao avaliar as alternativas, os consumidores decidem onde comprar, aliando necessidades a comodidade.

FATORES MOTIVADORES E AVALIADOS NA COMPRA DOS PEIXES
Os consumidores mencionaram oito motivadores para a compra de peixes, porém quatro (espécie desejada, oportunidade, menor preço e saúde) (Figura 1, Tabela 3) respondem por 94,4\% das citações. Esses motivadores são definidos por Schiffman e Kanuk (2000), Kotler e Keller (2006), Teixeira (2010), Sonoda et al. (2012) e Maciel et al. (2015) como fator cultural (espécie desejada), fator social (oportunidade), fator econômico (preço menor) e fator psicológico (saúde). 
Figura 1. Motivadores do consumo de peixes de acordo com o local de compra.

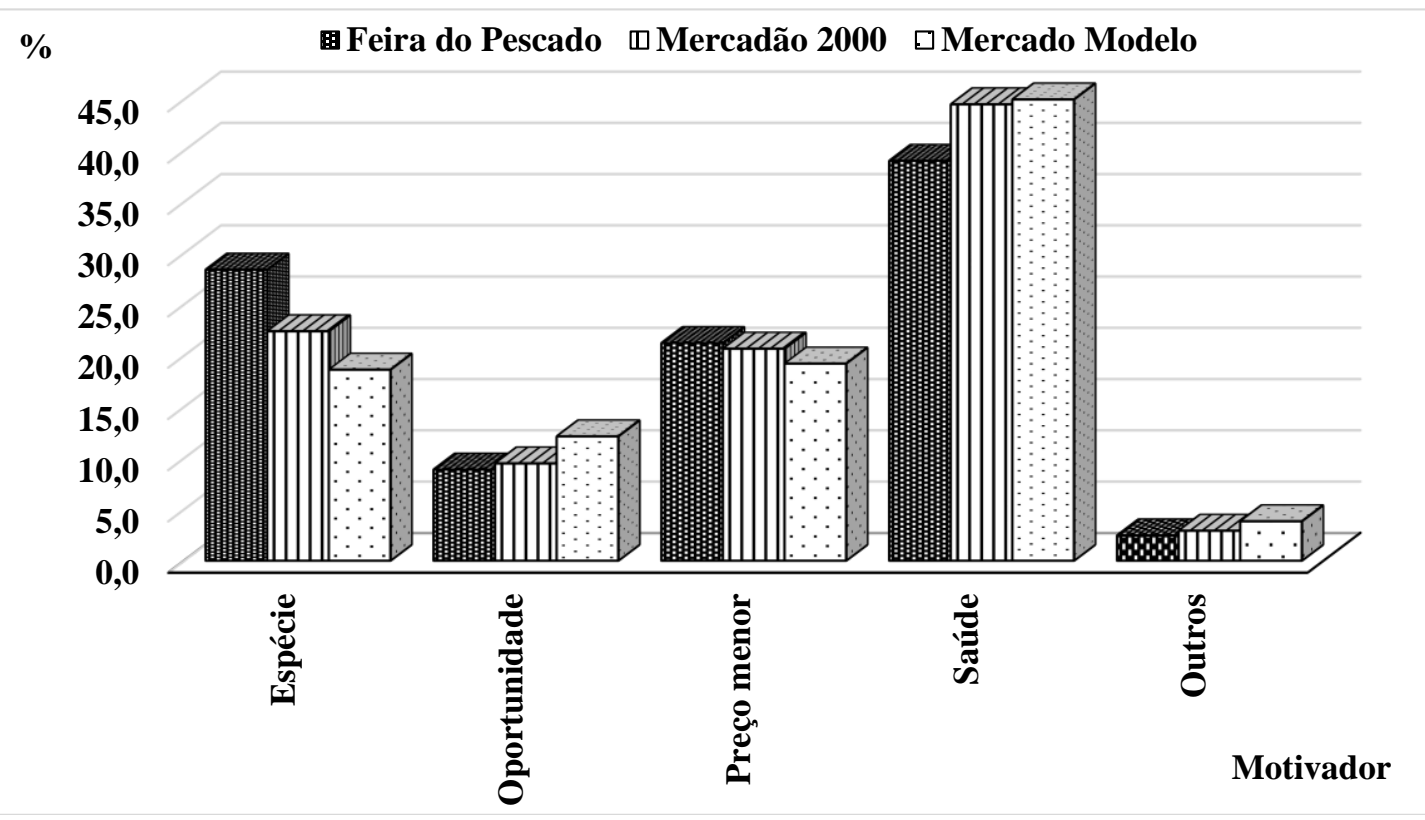

Fonte: Elaborado pelo Autor.

Tabela 3. Variação percentual dos motivadores do consumo de peixes citados de acordo com o local de compra e classe de renda.

\begin{tabular}{|c|c|c|c|c|c|c|}
\hline Mercado & Classe Social & Oportunidade & Preço menor & Espécie & Saúde & Outros \\
\hline \multirow{5}{*}{ 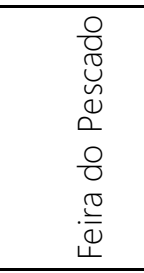 } & A & 33,3 & - & - & 66,7 & - \\
\hline & B & 18,0 & 18,0 & 18,0 & 46,0 & - \\
\hline & C & 4,0 & 12,0 & 32,0 & 44,0 & 8,0 \\
\hline & $D$ & 10,6 & 19,1 & 30,3 & 37,8 & 2,1 \\
\hline & E & 7,1 & 25,0 & 26,6 & 39,1 & 2,2 \\
\hline \multirow{5}{*}{$\begin{array}{l}8 \\
8 \\
0 \\
\sim \\
0 \\
\frac{2 \pi}{0} \\
\frac{0}{0} \\
\frac{0}{0} \\
\sum\end{array}$} & A & 50,0 & - & - & 50,0 & - \\
\hline & B & 14,3 & - & 28,6 & 57,1 & - \\
\hline & C & 17,8 & 13,3 & 26,7 & 40,0 & 2,2 \\
\hline & $\mathrm{D}$ & 6,0 & 21,0 & 25,0 & 45,0 & 3,0 \\
\hline & $E$ & 10,8 & 23,6 & 17,8 & 44,6 & 3,2 \\
\hline \multirow{5}{*}{$\begin{array}{l}\frac{0}{0} \\
\frac{0}{0} \\
\sum \\
\frac{0}{2} \\
\frac{0}{0} \\
\frac{0}{0} \\
\frac{0}{2}\end{array}$} & A & - & - & - & 100,0 & - \\
\hline & B & - & - & 25,0 & 75,0 & - \\
\hline & C & 8,0 & 12,0 & 28,0 & 44,0 & 8,0 \\
\hline & D & 9,2 & 19,3 & 20,2 & 47,9 & 3,4 \\
\hline & E & 14,8 & 20,6 & 16,4 & 44,4 & 3,7 \\
\hline
\end{tabular}

Fonte: Elaborado pelo Autor.

No contexto geral o maior destaque foi direcionado ao motivador saúde (43,1\%), seguido da espécie de peixe desejada (23,4\%), o preço menor de algumas espécies (20,5\%) e a oportunidade para a compra (10,1\%), porém, com importância percentual distinta entre os mercados e classes 
sociais. De acordo com os consumidores, o motivador saúde se relaciona ao peixe como alimento mais saudável que os demais itens alimentares e seu consumo colaborar para uma saúde melhor, como descrito nos relatos: "A gordura do peixe é mais saudável que o da carne e faz bem pra saúde"; "Quando como peixe não tenho problema de digestão porque é um alimento mais leve"; "Fui operada e só posso comer peixe no momento porque é mais leve" e "Tenho problema de coração e pressão alta, o médico disse para eu comer bastante peixe", corroborando com o estudo de Sartori e Amancio (2012) e Rocha, Rosanova e Silva (2015) que apontam os benefícios do consumo de peixes à saúde.

Esse motivador tem maior importância percentual para os consumidores das classes sociais " $A$ " $e^{\text {" }} B$ ", o que pode estar relacionado ao maior esclarecimento que os consumidores dessas classes podem possuir frente a contribuição do consumo de proteína derivada do peixe para a saúde (NORONHA; ANDRADE, 2005; BARBOSA FILHO; PESSÔA, 2008; SANTOS; DAMASCENO, 2011; SANTOS et al., 2015), porém, a importância percentual decresce para as classes sociais de menor renda.

O Mercado Modelo foi o local de compra do peixe onde esse motivador obteve maior destaque, seguido do Mercadão 2000 e da Feira do Pescado. De acordo com os relatos obtidos, o que explica esse diferencial entre os mercados se concentra no contexto tradição, pois a ordem de importância é ligada ao tempo de funcionamento do mercado e a cultura local (DOTTO, 1999).

A espécie desejada é um fator cultural tradicional na região amazônica, onde a preferência por uma determinada espécie de peixe é marcante, como no caso do tambaqui (Colossoma macropomum) e do pirarucu (Arapaima spp.), que devido a preferência popular, já apresentaram sinais de sobrepesca, demandando medidas legais de limitações e proibições da captura e comercialização (GANDRA, 2010; AYALA, 2013). Esse fator tem maior participação percentual na Feira do Pescado, onde se observou o maior quantitativo de espécies de peixes diferentes ofertadas aos consumidores, resultado da participação do pescador na venda direta ao consumidor, pois a 
tendência dos permissionários é comprar grandes volumes de poucas espécies para comercializar, enquanto os pescadores disponibilizam uma quantidade menor de peixes, porém como uma variedade maior de espécies.

A escolha da espécie perde importância percentual em direção às classes sociais de menor renda, principalmente para os consumidores do Mercado Modelo, pois é nesse mercado que alguns consumidores das classes " $\mathrm{D}$ " e "E" relataram comprar o que é conhecido regionalmente como "salada" ou "misturado" (cambada ou conjunto de peixes de espécies diferentes com pequeno porte comercializado em conjunto por um determinado preço) (PRO-VÁRZEA, 2007). No outro extremo das classes sociais, a ausência de citações dos consumidores da classe "A" para esse motivador em todos os pontos de venda visitados se justifica no poder de compra que têm para adquirir a espécie desejada, independentemente do ponto de venda, destacadas nos seguintes relatos: "Tenho um pescador que traz os peixes que eu quero toda a semana", "Encomendo o peixe de outros municípios, onde tenho parentes, lá a pesca é mais fácil" e "Quando eu quero um tambaqui vou em qualquer mercado e compro, não tenho muito tempo para escolher lugar, eu vejo se tem que eu quero e compro".

$\bigcirc$ preço menor dos peixes tem maior importância percentual para as classes de menor poder aquisitivo, sem menção desse motivador para os consumidores da classe social "A" e pouca para a classe "B". A Feira do Pescado foi o ponto de venda de peixes onde a importância percentual foi maior, o que pode estar relacionado a sua característica, como local onde parte das espécies comercializadas vem diretamente dos pescadores, que tendem a praticar um menor preço devido a saída do permissionário da cadeia de comercialização, descrita nos estudos realizados pelo Pro-Várzea (2007).

Mercado Modelo foi o local com maior participação percentual de consumidores das classes sociais "D" e " $E$ ", principalmente os provenientes da classe "E" da Zona Rural, que por terem menor poder aquisitivo, aproveitam para comprar peixes em cambada ou salgados 
de menor preço, após a venda da produção da agricultura familiar.

motivador oportunidade tem maior importante para os consumidores que frequentam o Mercado Modelo e menor na Feira do Pescado. Essa menor importância da Feira do Pescado se deve à ausência de infraestrutura para a venda de outros produtos (frutas, verduras e grãos) e sua distância para o Centro Comercial de Santarém, enquanto o Mercadão 2000 oferece a oportunidade para a compra de outros produtos nos estabelecimentos circunvizinhos e o Mercado Modelo, a oportunidade para a comercialização da produção rural principalmente na Feira da Candilha, descrito nos fatores de escolha do local de compra de peixes (SEMENIK; BAMOSSY, 1995; BOONE; KURTZ, 1998; KOTLER; KELLER, 2006).

Os consumidores Santarenos mencionaram dez fatores avaliados na compra de peixes, porém cinco (espécie desejada, higiene, preço, qualidade e tamanho) (Figura 2, Tabela 4) respondem por $92,8 \%$ do total. A qualidade foi o item de destaque $(37,4 \%)$, seguida da espécie desejada (22,3\%), o preço $(21,3 \%)$, a higiene $(6,3 \%)$ e o tamanho dos peixes comercializados (5,5\%). Assim como os fatores motivadores, os fatores avaliados são descritos por Schiffman e Kanuk (2000) e Kotler e Keller (2006) como fatores culturais (espécie desejada, tamanho dos peixes e qualidade), econômico (preço) e sociais (higiene, saúde).

A qualidade, traduzida como frescor do peixe (MOURA et al., 2009; SANTOS, 2011; SOARES; GONÇALVES, 2012) foi relatada pelos consumidores nas declarações: "Quando vou comprar o peixe vejo se está fresco, avalio as guelras vermelhas, olhos brilhantes e músculo durinho"; "Avalio a saúde do peixe, vejo se é novo" e "Pra mim o que importa é a qualidade do peixe". Esse fator tem maior destaque na Feira do Pescado, onde os consumidores têm a possibilidade de comprar peixes diretamente dos pescadores e onde os pescadores filiados a Colônia de Pescadores de Santarém (Z20) desembarcam sua produção para venda aos permissionários, após a coleta de informações de desembarque, realizada diariamente pela Z-20. 
Esse contexto faz com que a descritos no estudo de Brisola e Castro qualidade tenha importância superior ao (2006).

preço do peixe, diferindo dos resultados

Figura 2. Fatores avaliados pelos consumidores de peixes Santarenos de acordo com o local de compra.

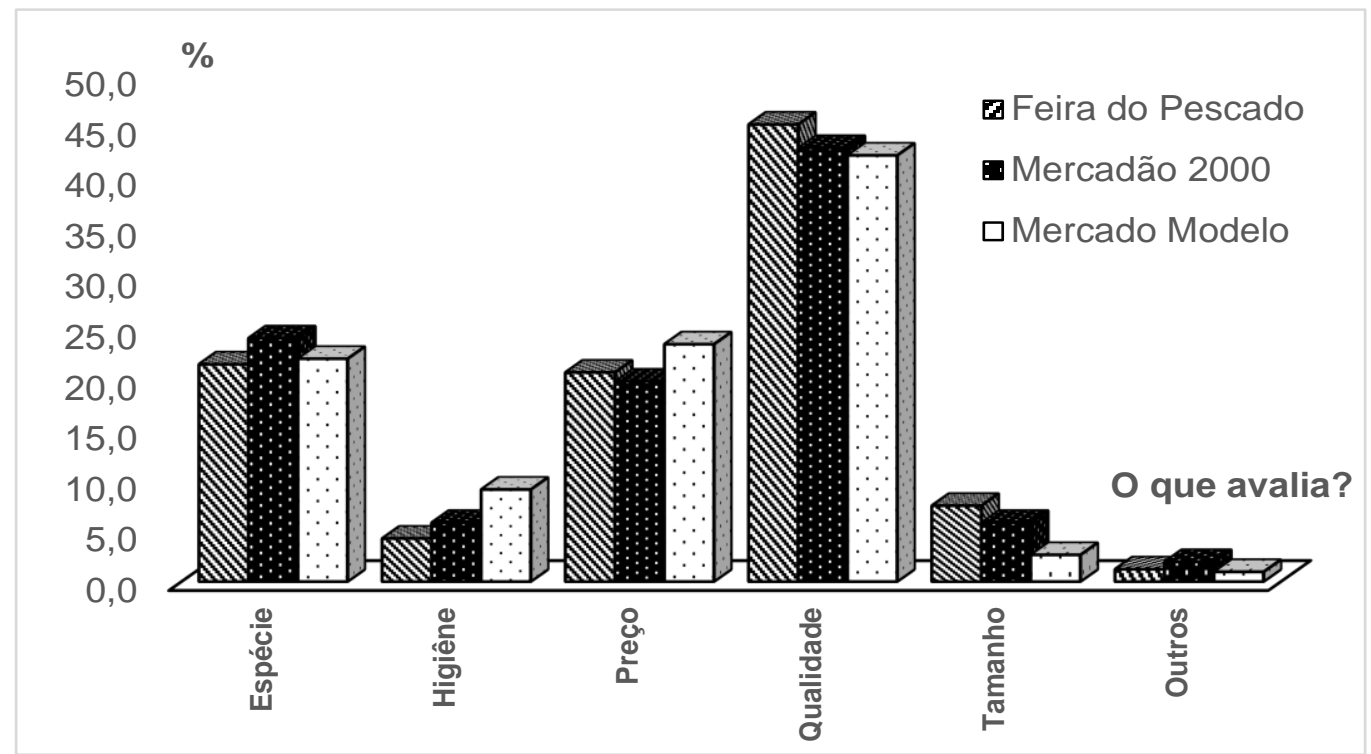

Fonte: Elaborado pelo Autor.

Tabela 4. Variação percentual dos fatores avaliados pelos consumidores de peixes Santarenos de acordo com o local de compra e classe de renda.

\begin{tabular}{|c|c|c|c|c|c|c|c|}
\hline Mercado & Classe Social & Espécie & Higiene & Preço & Qualidade & Tamanho & Outros \\
\hline \multirow{5}{*}{ 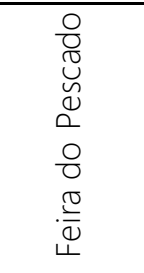 } & $A$ & 0,0 & 0,0 & 14,3 & 85,7 & 0,0 & 0,0 \\
\hline & B & 0,0 & 0,0 & 0,0 & 100,0 & 0,0 & 0,0 \\
\hline & C & 19,2 & 0,0 & 7,7 & 61,5 & 7,7 & 3,8 \\
\hline & D & 23,0 & 6,1 & 19,1 & 44,8 & 6,5 & 0,4 \\
\hline & E & 21,7 & 3,2 & 24,9 & 39,4 & 9,0 & 1,8 \\
\hline \multirow{5}{*}{$\begin{array}{l}8 \\
\stackrel{0}{0} \\
0 \\
\frac{2 \pi}{0} \\
\frac{0}{0} \\
\frac{0}{0} \\
\sum\end{array}$} & $A$ & 50,0 & 0,0 & 0,0 & 50,0 & 0,0 & 0,0 \\
\hline & B & 0,0 & 14,3 & 0,0 & 85,7 & 0,0 & 0,0 \\
\hline & C & 30,0 & 3,3 & 10,0 & 53,3 & 3,3 & 0,0 \\
\hline & D & 24,5 & 6,8 & 16,6 & 44,2 & 5,7 & 2,3 \\
\hline & E & 21,5 & 5,0 & 28,7 & 35,4 & 7,2 & 2,2 \\
\hline \multirow{5}{*}{$\begin{array}{l}\frac{0}{0} \\
\frac{0}{0} \\
\sum \\
\frac{0}{0} \\
\frac{0}{0} \\
\frac{0}{2} \\
\frac{0}{z}\end{array}$} & A & 0,0 & 0,0 & 0,0 & 100,0 & 0,0 & 0,0 \\
\hline & B & 50,0 & 0,0 & 0,0 & 50,0 & 0,0 & 0,0 \\
\hline & C & 35,5 & 0,0 & 19,4 & 41,9 & 0,0 & 3,2 \\
\hline & D & 21,7 & 10,2 & 20,4 & 43,3 & 3,8 & 0,6 \\
\hline & E & 19,9 & 9,7 & 26,5 & 40,7 & 2,2 & 0,9 \\
\hline
\end{tabular}

Fonte: Elaborado pelo Autor. 
O Mercadão 2000 por sua proximidade da Feira do Pescado, pode ofertar aos consumidores peixes com frescor equivalente aos comercializados na Feira do Pescado e, portanto, se descartou como segundo local mais procurado quando o fator avaliado é a qualidade. $\bigcirc$ fato da qualidade ter destaque como principal fator avaliado no momento da compra dos peixes corrobora com Schiffman e Kanuk (2000) e Kotler e Keller (2006) porém, na ótica do presente estudo, esse fator perde importância percentual na direção das classes sociais de menor poder aquisitivo, devido a limitação financeira (ROCHA NETO, 2010; SILVEIRA et al., 2012).

Os consumidores Santarenos mencionaram adquirir 29 etnoespécies', onde 10 são categorizados como bagres e 19 como peixes de escamas. Dessas, 10 respondem por 83,1\% da procura total, com destaque para o tambaqui (19,5\%), o tucunaré (Cichla spp.) (11,9\%) e o curimatã (Prochilodus nigricans) (10,1\%). Com base no catálogo de Peixes Comerciais do Médio Amazonas, Região de Santarém

\footnotetext{
${ }^{1}$ Etnoespécie refere-se a um grupo específico de espécie comercializada. Assim, no contexto desta pesquisa significa nome local e comum do grupo
}

(FERREIRA, 1998), foi possível estimar que as 29 etnoespécies podem totalizar 79 espécies utilizadas para o consumo, corroborando com os estudos de Gonçalves e Batista (2008), Gandra (2010) e Faria-Junior (2013).

A Feira do Pescado e o Mercadão 2000 foram os pontos com maior número de estnoespécies ofertadas (29), enquanto o Mercado Modelo ofertou 24, o que pode ser um dos motivos da maior frequência de consumidores na Feira do Pescado e no Mercadão 2000 (Item 3.1). Apesar desse diferencial na procura, a importância da espécie desejada reduziu percentualmente em direção as classes de menor renda, que compensam a impossibilidade de adquirir uma determinada espécie devido sua limitação financeira, utilizando um maior quantitativo de espécies de menor valor comercial (menor preço), o que aponta para a maior importância do preço para os consumidores de menor poder aquisitivo (BRISOLA; CASTRO, 2006).

Como observado, o fator preço interfere na escolha do consumidor pela

taxonômico comercializado (COSTA NETO; PACHECO, 2005) 
espécie a ser adquirida, corroborando com os estudos realizados por Mariuzzo (2005), bem como na distribuição dos consumidores nos pontos estudados. Nessa ótica, os resultados permitiram observar que o preço ganha importância para as classes sociais de menor poder aquisitivo (Figura 2, Tabela 4) que representam cerca de 98,7\% da população local (IBGE, 2012), 98,0\% dos consumidores amostrados e que ao nível nacional, representam três quartos das famílias brasileiras (CHAUVEL; MATTOS, 2008). E que o Mercado Modelo e a Feira do Pescado são os pontos onde o maior quantitativo de etnoespécies com valor comercial abaixo de $\mathrm{R} \$ 10,00 / \mathrm{kg}$ são comercializadas $\quad(50,0 \%$ e $\quad 72,4 \%$ respectivamente), corroborando com Barbosa (2006), o que alerta para o perfil do consumidor Paraense de pescado, onde destaca que "os consumidores estão mais exigentes e, dentre outras exigências, procuram produtos que apresentam preço acessível", o que corrobora com os resultados obtidos, onde se observa um maior número de fatores motivacionais do consumo, principalmente para as classes sociais de menor poder aquisitivo, e onde o preço foi avaliado em função da capacidade de compra (preço acessível) de acordo com a classe social (ROCHA NETO, 2010; SILVEIRA et al., 2012).

A higiene do local de comercialização é o manuseio dos peixes ao longo do processo de comercialização são fatores que perdem importância para os consumidores das classes sociais de menor poder aquisitivo (Tabela 4). Esse ponto foi observado em todos os mercados onde os permissionários prestam o serviço gratuito de escamação (retirada da escama), evisceração e ticagem (cortes transversais para a fragmentação das espinhas intermusculares) de algumas espécies de peixes no intuito de atrair clientes, ou os próprios consumidores contratam os serviços de terceiros na própria dependência do mercado com essa finalidade (COELHO, 2015).

O tamanho do peixe (porte da espécie desejada - exemplar de pequeno, médio ou grande porte), mencionado somente por consumidores das classes sociais "C", "D" e "E" apresenta tendências de aumento de importância para os 
consumidores de menor poder aquisitivo, sendo mais representativa na Feira do Pescado (Tabela 4), onde os consumidores podem escolher uma maior amplitude de porte para cada espécie desejada, ressaltando que os exemplares menores de cada espécie possuem um menor valor comercial, dessa forma, podem em alguns casos, comprar a espécie desejada mesmo que de menor porte.

O atributo "outros" se direciona as citações relacionadas ao desejo dos consumidores em variar o cardápio, a preferência pelo sabor dos peixes frente a outros itens alimentares (carne e frango), a consciência ambiental, a satisfação e confiança no atendimento recebido (KUBITZA, 2002; KOTLER; KELLER, 2006), mencionadas como: "Gosto de variar o cardápio na minha casa, comendo peixe na semana", "Só compro com esse vendedor, porque sei que o peixe dele é novo e não me engana", "Não confio em qualquer um que vende peixe, tenho que conhecer para comprar", "Vejo a legalidade dos peixes, verificando se determinada espécie está no defeso", "Se estiver proibido não compro, porque senão estou contribuindo para a diminuição daquela espécie", "No mercado posso escolher a espécie", "No mercado tem mais peixe" e "Prefiro comprar aqui porque sei que é fresco".

Nessa ótica, um conjunto de fatores (BARBOSA, 2006; KOTLER, 2006; LOPES et al., 2010, SILVA et al., 2010; SANTOS; DAMASCENO, 2011; SOLOMON, 2011) influenciam a decisão do consumidor, corroborando com Santos e Santos (2005), que mencionam além do preço pago pelo peixe, o tipo e tamanho deste e o local de venda.

No âmbito mercadológico o relato de Kotler (2006) de que "a cultura é o determinante mais fundamental dos desejos e do comportamento de uma pessoa" corrobora com o fato do consumidor Santareno ter a cultura de consumir mais pescado que os consumidores de outras regiões geográficas do território brasileiro (SARTORI; AMANCIO, 2012).

No contexto geral, a tendência de comportamento dos consumidores das Classes Sociais "A" e "B" apresentam semelhanças, assim como os das Classe "C", "D" e "E", com maior destaque para as 
duas últimas, quanto a importância dada aos fatores apresentados, corroborando com Kotler (2009), devido a relativa homogeneidade e compartilhamento de valores e interesses, apresentando comportamentos similares.

\section{CONCLUSÃO}

A análise do comportamento do consumidor Santareno na escolha do local de compra e dos fatores motivadores e avaliados no momento da compra de peixes realizado com base na Classe Social permite observar tendências gerais e semelhanças. Que variam quantitativamente (número de fatores avaliados) e qualitativamente (importância relativa).

As tendências gerais se relacionam a escolha pelo Mercadão 2000 como principal local de compra por oferecer outros produtos além do peixe, assim como para a Feira do Pescado em segundo plano, por se localizar nas proximidades dos Mercadão 2000. Nas semelhanças se destaca a maior participação de consumidores das Classes Sociais de maior poder aquisitivo nesses mercados, enquanto os consumidores da
Classe Social "E" se direcionam principalmente para o Mercado Modelo, com destaque para os originários da Zona Rural, que aliam interesses e necessidades.

Entre os fatores motivadores e avaliados no momento da compra de peixes, a aquisição de um produto saudável e de qualidade é uma tendência geral de maior importância, seguida da espécie desejada e do preço, independente da Classe Social, enquanto as semelhanças se direcionam ao grau de importância que os consumidores atribuem a esses fatores. Enquanto os Fatores Saúde, Qualidade e Espécies têm maior importância para os consumidores das Classes Sociais de maior poder aquisitivo, o preço ganha importância de forma inversa, o que serve de alerta para os gestores Paraenses e Brasileiros, quanto à atenção que deve ser dada para o peixe, um produto de elevado valor nutricional e base para a alimentação da população da região da área de estudo e da Amazônia.

Nesse sentido, no contexto geral o fator econômico relacionado a limitação financeira como determinante na decisão 
e escolha de um determinado produto, neste estudo foi precedido nos fatores motivadores da compra do peixe pelos fatores saúde e espécie de peixe desejada, já para os fatores avaliados na compra, pela qualidade do produto e a espécie de peixe desejada, ficando o fator econômico preço na terceira posição. Porém, é clara a importância desse fator para grande parte dos consumidores Santarenos, que pertencem às classes sociais " $D$ " $e^{\text {" }} E$ ", que tendem a procurar o mercado que ofereça espécies de peixes com valores comerciais mais baixos.

Esses dados ressaltam a importância dos Fatores que influenciam a compra de peixes por classe social no município de Santarém-PA para o consumidor no âmbito do mercado pesqueiro, promovendo conhecimento sócioeconômico que ressalta informações acerca do perfil deste, bem como do mercado pesqueiro o que favorece a aquisição e aceitação de pescado. Através da caracterização e sintonia entre consumidores e suas respectivas classes sociais com o mercado através do local de compra, fatores motivacionais e avaliados no ato da compra, favorecendo a saúde e qualidade quanto fatores primordiais ao consumo em detrimento da classe social, isto é o consumidor favorece um produto com qualidade a fim de manter-se saudável.

Finalmente, os resultados obtidos destacaram a importância do pescado para o consumo da população santarena que depende dos mercados e feiras da cidade. As evidencias apresentadas sugerem a urgente necessidade de discussão sobre as estratégias e táticas de gestão sobre o recurso pesqueiro na região, incluindo ações de monitoramento pesqueiro. Um colapso ou a redução drástica na produção pesqueira pode desencadear vários efeitos sócio-econômicos negativos e ainda não previsíveis.

\section{REFERÊNCIAS}

AMOROSO, M.C.M. Alimentação em um bairro pobre de Manaus, Amazonas. Acta Amazônica, v. 11(supl. 3), p. 1-43, 1981.

AYALA, D.M. Dinâmica pesqueira e estrutura populacional da jatuarana (Brycon amazônicos) comercializada nas porções alta e média da bacia do rio Madeira. Porto Velho-RO, 2013. 59p. Dissertação (mestrado em Desenvolvimento regional e Meio 
Ambiente) - Fundação Universidade Federal de Rondônia), UFRO, 2013.

BARBOSA, J.A. Características comportamentais do consumidor de peixe no mercado de Belém. Boletim Técnico Científico do CEPNOR. Belém, (1): 115-133, 2006.

BARBOSA FILHO, F. de H.; PESSÔA, S. "Retornos da educação no Brasil". Pesquisa e Planejamento Econômico, 38(1): 97-125, 2008.

BOONE, L.E.; KURTZ, D.L. Marketing contemporâneo. 8. ed. Rio de Janeiro: LTC - Livros Técnicos e Científicos, 1998.

BRISOLA, M. V.; CASTRO, A. M. G. O consumidor de carne bovina do Distrito Federal-Quanto paga e que atributos de valor o fariam pagar mais. Cadernos de Ciência \& Tecnologia, v. 23, n. 1, p. 95-125, 2006.

CAMEIRO, P.; BARROS, L.C.G.; ANJOS, G.M.; MARTINS, A.S.; SANTOS, E.J.S. E SILVA, C.A. Comercialização do tambaqui (Colossoma macropum) na cidade de Penedo - Al. Ministério da Agricultura, Pecuária e Abastecimento, 2007.

CARVALHO, M.J.S.L. Os Fatores que influenciam no processo decisório de compra do consumidor: um estudo de caso em um comércio varejista do ramo de tecidos na cidade de Picos-PI. Monografia (Especialização em Administração) Universidade Federal de Piauí - UFPI, 2012.

CERDEIRA, R.G.P.; RUFFINO, M.L.; ISAAC, V.J. Consumo de peixes e outros alimentos nas comunidades ribeirinhas do
Lago Grande de Monte Alegre. Acta Amazônica, 27(3): 213-227, 1997.

CHAUVEL, M.A.; MATTOS, M.P. de A.Z. Consumidores de Baixa Renda: Uma Revisão dos Achados de Estudos Fetos no Brasil. Cadernos EBAPE. BR, v. 6, n. 2, Jun. 2008

COELHO, A.C. de S. Indicadores do consumo de peixes como ferramenta de apoio a gestão dos recursos pesqueiros no município de Santarém-PA. SantarémPA, 2015. 50p. Dissertação (mestrado em Recursos Aquáticos Continentais Amazônicos - PPGRACAM) Universidade Federal do Oeste do Pará/UFOPA, Instituto de Ciências e Tecnologias das Águas/ICTA, 2015.

COSTA, T.V.; SILVA, R.R.S.; SOUZA, J.L.; BATALHA, O.S.; HOSHIBA, M.A. Aspectos do consumo e comércio de pescado em Parintins. Boletim do Instituto de Pesca, São Paulo, v. 39, n. 1, p. 63 - 75, 2013.

DOTTO, D. M. R. Mercado da carne de peixe de água doce em Santa Cruz do Sul / RS / Brasil: uma análise do comportamento do consumidor. Santa Cruz do Sul: Universidade Federal do Rio Grande do Sul, 1999. 112f. Dissertação (Mestrado em desenvolvimento Regional). UFRS, 1999.

ENGEL, J.F.; BLACKWELL, R.D.; MINIARD, W.P. Comportamento do consumidor. 8.ed. Rio de Janeiro: LTC, 2000.

FPA (FUNDAÇÃO PERSEU ABRAMO). Classes Sociais no Brasil de Hoje. Fundação Perseu Abramo - Partido dos Trabalhadores. Ed. 1 de maio de 2013. 79p. 
GANDRA A.L. O mercado de peixes da região metropolitana de Manaus. Relatório INFOPESCA. Série: O mercado de peixes nas grandes cidades latinoamericanas. Montevidéu: INFOPESCA. 2010.

FREIRE, J.; OLIVEIRA, A.; AZEVEDO, M.; SOUZA, I.; PINHEIRO, M.; MATANGRANO, R.; NASCIMENTO, D.; CASTRO, M.; CUNHA, M.; MARÇAL, L.; SOUZA, A.; PEREIRA, M. Perfil socioeconômico do consumidor de pescado no município de Belém - PA. 19 ENCONTRO NACIONAL DE GRUPOS PET. Anais... Santa Maria - Rio Grande do Sul, 2014.

GONÇALVES, C; BATISTA, V. S. Avaliação do desembarque pesqueiro efetuado em Manacapuru, Amazonas, Brasil. Acta Amazônica, Vol. 38 (1) 2008: 135-144, 2010.

Instituto Brasileiro de Geografia e Estatística (IBGE). Contagem da população em 2010 (Censo demográfico). 2012.

ISAAC, V. J.; RUFFINO, M. L. A Estatística pesqueira no Baixo Amazonas: experiência do Projeto IARA. In: Recursos Pesqueiros do Médio Amazonas: biologia e estatística pesqueira. Brasilia: Edições Ibama. cap.9, p.201-224, 2000.

ISAAC, V.J. O peixe nosso de cada dia. Revista Virtual da Iniciação Acadêmica, 2002. Disponível em: <http://www. propesp.ufpa.br>. Acesso em: 26 Fev. 2014.

ISAAC, V. J.; ALMEIDA, M. C. El consumo de peixes em la Amazônia Brasileña. Relatório FAO. Roma: FAO, 2011.
KARSAKLIAN, E. Comportamento do consumidor. $2^{\mathrm{a}}$. ed., $3^{\mathrm{a}}$. reimpressão, São Paulo: Atlas, 2008.

KOTLER, P. Administração de marketing: análise, planejamento, implementação e controle. 5. ed. São Paulo: Atlas, 1998.

KOTLER, P.; KELLER, K.L. Administração de marketing. 12 ed. São Paulo: Pearson Prentice Hall. 2006.

KOTLER, P. Administração de marketing: análise, planejamento, implementação e controle. Trad. Ailton Bomfim Brandão. 5 ed. 8 reimpressão. São Paulo: Atlas, 2009.

KUBITZA, F. Com a palavra os consumidores. Panorama da Aquicultura, v. 69, p. 48-53, 2002.

LIRA, G. M.; PEREIRA, W. D.; ATHAYDE, A. H.; PINTO, K. P. Avaliação da qualidade de peixes comercializados na cidade de Maceió - AL. Revista. Higiene Alimentar, São Paulo. v.15, n. 84, p. 67 - 72, mai., 2001.

LOPES, M.L.B.; COSTA, P.A.; SANTOS, J.S.B.; CUNHA, S.G.T.; SANTOS, M.A.S. Mercado e dinâmica espacial da cadeia produtiva da pesca e aquicultura e aquicultura na Amazônia. Estudos Setoriais, 7. Banco da Amazônia, Belém Pará. 51p, 2010.

MACHADO, A.S.G.; BIANCHINI, C.B. Caracterização dos consumidores de pescado comercializados na feira do peixe de Porto Alegre-RS. 25 CONGRESSO BRASILEIRO DE CIÊNCIA E TECNOLOGIA DE ALIMENTOS, 2016. Anais... Gramado RS: FAURGS, 2016. 
MACIEL, E.S. Perspectiva do consumidor perante produto proveniente da cadeia produtiva de tilápia do Nilo rastreada (Oreochromis niloticus) consumo de pescado e qualidade de vida. Tese de Doutorado. Centro de Energia Nuclear na Agricultura, Universidade de São Paulo. 299p., 2011.

MACIEL, E. D. S.; SAVAY-DA-SILVA L. K.; GALVÃO J. A.; OETTERER, M. Atributos de qualidade do pescado relacionados ao consumo na cidade de Corumbá, MS. Boletim do Instituto de Pesca. v. 41, n. 1, p. 199-206, 2015.

MARIUZZO, D. Segurança Alimentar: Certificação EUREPGAP IFA. 13 SEMINÁRIO NACIONAL DE CRIADORES E PESQUISADORES. Anais... Tecnologias para o Melhoramento Genético. Ribeirão Preto: ANCP, 2005.

MELO, J. F. B.; SANTOS, A. S.; DAMASCENO, A. A. Comercialização e perfil do consumidor da carne de peixe na região do semiárido de Juazeiro (BA) e Petrolina (PE). Informações Econômicas, São Paulo, SP, v. 41, n. 12, dez., 2011.

MERONA, B.; BITTENCOURT. Mercado de Manaus. Resultados, v. 48 (Supl. 2), p. 433-455, 1988.

MERONA, B de. Pesca e ecologia dos recursos aquáticos na Amazônia. Povos das águas - realidade e perspectiva na Amazônia. Belém, MPEG/UFPA. p.159$185,1993$.

MINAYO, M.C.S. Pesquisa Social: teoria, método e criatividade. 9. ed. Petrópolis: vozes, 1998.
MOURA, M. A. M. de; GALVÃO, J. A.; HENRIQUE, S. M.; SAVAY DA SILVA, L. K.; OETTERER, M. Caracterização físicoquímica e de frescor de filés de tilápia do Nilo (Oreochromis niloticus) oriundas da pesca extrativista no médio rio Tietê/SP, Brasil. Boletim do Instituto de Pesca, São Paulo, v. 35, n. 3, p. 487-495, 2009.

NORONHA, K. V. M. S.; ANDRADE, M. V. $\bigcirc$ Efeito da Distribuição de Renda Sobre - Estado de Saúde Individual no Brasil. Anais da Anpec, 2005.

PAGANO, M.; GAUVREAU, K. Princípios de Bioestatística. Tradução da $2^{a}$ edição norte-americana. São Paulo: Pioneira Thomson Learning, 2004.

PINHEIRO, R. M; CASTRO, G. C. Comportamento do consumidor e pesquisa de mercado. Rio de Janeiro: Editora FGV, 2006.

PRO-VÁRZEA. O setor pesqueiro na Amazônia: análise da situação atual e tendências do desenvolvimento a indústria da pesca: Projeto Manejo dos Recursos Naturais da Várzea. Manaus: Ibama/Pro-Várzea, 2007.

ROCHA, A. S.; ROSANOVA, C.; SILVA, P. Perfil do Consumidor de Pescado no Município de Palmas-TO. 25 CONGRESSO BRASILEIRO DE ZOOTECNIA - ZOOTEC, 2015. Anais... Dimensões Tecnológicas e Sociais da Zootecnia. Fortaleza - CE, 2015.

ROCHA NETO, A. da P. Fatores que influenciam na decisão de compra de peixes nas feiras livres de Macapá - Ap. Monografia apresentada à Coordenação do Curso de Engenharia de Pesca da Universidade do Estado do Amapá, para 
obtenção de título de Bacharel em Engenharia de Pesca. Universidade do Estado do Amapá - UEAP. Macapá, 2010.

RODRIGUES, D. M. S. Perfil higiênicosanitário de feiras-livres do Distrito Federal e avaliação da satisfação de seus usuários. Monografia (Especialização em qualidade de alimentos) 64 f. 2004. Brasília: Universidade de Brasília, 2004.

RUFFINO, M.L. Potencialidade das várzeas para os recursos pesqueiros: uma visão sócio-econômica e ecológica. 1 WORKSHOP SOBRE AS POTENCIALIDADES DE USO DO ECOSSISTEMA DE VÁRZEAS DA AMAZÔNIA. Boa Vista, RR: EMBRAPA/CPAA, 1996.

RUFFINO, M.L. (eds.). A pesca e os recursos pesqueiros na Amazônia brasileira. Manaus: IBAMA. 262p., 2004.

SANTOS, A. P. B. Índices químicos, sensoriais e microbiológicos para a avaliação de frescor da pescada amarela (Cynoscion acoupa) armazenada em gelo. Dissertação (Mestrado em de Zootecnia e Engenharia de Alimentos) Universidade de São Paulo. Pirassununga-SP. 95p, 2011.

SANTOS, G. M.; SANTOS, A. C. M. Sustentabilidade da pesca na Amazônia. Estudos avançados, v. 19, n. 54, p. 165-182, 2005.

SANTOS, E. L.; SOARES, E. C.; SILVA, T. J.; JANUÁRIO, I. C. M.; GARCIA, S. C. S. Perfil do consumo de pescados na cidade de Coruripe, Alagoas. Acta Veterinaria Brasilica, v.9, n.2, p.153-159, 2015.

SARTORI, A. G. O.; AMANCIO, R. D. Pescado: importância nutricional e consumo no Brasil. Revista Segurança Alimentar e Nutricional, Campinas, v.19, n.2, p. 83-93, 2012.

SCHIFFMAN, L. G.; KANUK, L. L. Comportamento do consumidor. Tradução de Vicente Ambrósio. 6. ed. Rio de Janeiro: LTC.2000.

SEMENIK, R.; BAMOSSY, G. J. Princípios de marketing: uma perspectiva global. Tradução Lenke Peres. 1. ed. São Paulo: Makron Books, 1995.

SILVA; D. R. P.; ROCHA, E. A. O.; BRINGEL, M.G.B.; FILHO, O. P. M. Comportamento de compra: principais fatores que influenciam o consumidor. Revista Científica do ITPAC. v. 3. n. 4. Out., 2010.

SHRIMPTON, R.; GIUGLIANO, R.; RODRIGUES, N. M. Consumo de alimento e alguns nutrientes em Manaus. Acta Amazônica, v. 9, n. 1, p. 117-141, 1979.

SILVA, I. A.; LIMA, M. F.V; BRANDÃO, V. M.; DIAS, I. C. L.; SILVA, M. I. S.; LACERDA, L. M. Perfil de consumidores do pescado comercializado em mercados do município de São Luís, Maranhão, Brasil. Cadernos de Pesquisa, São Luís, v. 19, n. 1, Jan./Abr., 2012.

SILVA, N.M.N; SILVA, A.A.; BRAGA, T.M.P.; FARIA-JÚNIOR, C.H. Diagnóstico do comércio de Pirarucu nos mercados e feiras de Santarém, Pará. Biota Amazônia. Macapá, v. 6, n. 4, p.49-53, 2016.

SILVEIRA， L.S.; ABDALLAH， P.R.; HELLEBRANDT, L.; BARBOSA, M.N. e FEIJÓ, F.T. Análise socioeconômica do perfil dos consumidores de peixes no município de Rio Grande. Sinergia, Rio Grande, v. 16, n. 1, p. 9-19, 2012. 
SOARES, K.M.P.; GONÇALVES, A. A.

Qualidade e segurança do pescado. Revista do Instituto Adolfo Lutz. São Paulo, v. 71, n. 1, p. 1-10, 2012.

SOLOMON, M.R. Comportamento do Consumidor. 5 Ed., Porto Alegre: Bookman. 2002.

SONODA, D.Y.; CAMPOS, S.K.; CYRINO, J.E.P.; SHIROTA, R. Demand for fisheries products in Brazil. Scientia Agricola, v. 69, n. 5, p. 313-319, 2012.

TEIXEIRA, J.C.I. Fatores que influenciam o comportamento do consumidor.

Monografia (Especialização em Gestão Estratégica de Vendas e Negociação) Universidade Cândido Mendes. Rio de Janeiro - RJ, 2010.

TRONDSEN, T.; SCHOLDERER, J.; LUND, E.; EGGEN, A.E. Perceived barriers to consumption of fish among Norwegian women. Appetite, London, v. 41, n. 3, p. 301-314, 2003.

XAVIER, C.M.O; PEIXOTO, A.F.; FRANQUE, M.P. Perfil socioeconômico dos consumidores de pescado fresco comercializados em feiras livres da cidade de Garanhuns-PE. 3 JORNADA DE ENSINO, PESQUISA E EXTENSÃO - JEPEX, 2013. Anais... Recife: UFRPE, 2013.

ZAR, J. H.; Biostatystical Analisys. 4ed. Ed.Prentice-Hall. 1999. 661p. 